\title{
An Investigation into Receptive Vocabulary Growth and Its Predictability for Reading Development of University Students in a Semester Course
}

\section{Zahid Hussain Pathan}

Graduate Research Student, School of Educational Studies, Universiti Sains Malaysia, pathanzahid82@yahoo.com

\section{Shaik Abdul Malik Mohamed Ismail}

Assoc. Prof., corresponding author, School of Educational Studies, Universiti Sains Malaysia,samohame@gmail.com

\section{Niaz Hussain Soomro}

$\mathrm{PhD}$, Senior Lecturer, University of Balochistan, Quetta, Pakistan, soomroniaz9@gmail.com
The present study primarily aims to investigate the relationship between Pakistani students' receptive vocabulary growth and their reading development at two different points: at the beginning and the end of English course. The standardized vocabulary size test (VST) and reading comprehension test (TOEFL) were administered to 123 first year postgraduate university students. To analyse the data, both descriptive and inferential tests were performed in SPSS (version, 21). The findings of the descriptive statistics showed a change in the mean scores of participants' vocabulary on 14,000 words list at the beginning of the English course $(M=35.00)$ and $(M=40.80)$ at the end of the English course respectively. The findings of the paired t-test revealed that the change was significant at $\mathrm{p}<.001$. The findings of correlation test indicated that students' vocabulary size and their reading ability were closely associated at $(\mathrm{r}=.76)$. The findings of the simple linear regression also generated acceptable model where $58.2 \%$ of the variance in the dependent variable (reading comprehension) was predicted by the independent variable (vocabulary size). This study has some implications for teaching and learning of the English language.

Keywords: semester course, correlation between VST and reading at two different points, dynamicity of vocabulary size, students' receptive vocabulary growth, EFL

Citation: Pathan, Z. H., Ismail, S. A. M. M., \& Soomro, N. H. (2019). An Investigation into Receptive Vocabulary Growth and Its Predictability for Reading Development of University Students in a Semester Course. International Journal of Instruction, 12(1), 797-808. https://doi.org/10.29333/iji.2019.12151a 


\section{INTRODUCTION}

Prior researches have drawn the pivotal importance of vocabulary in ESL/EFL learning (Bauer \& Nation, 1993; Cheng, 2007; Fan, 2000; Nation, 2001; Schmitt, 2000), and labelled it as an indispensable variable that positively affects students' academic reading (Kaivanpanah, \& Zandi, 2009; Qian, 2002). Zimmermann (1997, p. 4) states, "Reading is fundamental to success in life and it opens the door to virtually all other learning", and successful academic reading is heavily dependent on vocabulary (Koda, 2005). In the similar vein, Laufer (1997) states, "No text comprehension is possible, either in one's native language or in a foreign language, without understanding the text's vocabulary" (p. 20). Similarly, Hu and Nation (2000) states that the amount of unfamiliar and familiar words also determine the complications of a text. Moreover, Stahl (2003, p. 241) holds the opinion that the relationship between these two variables is a "robust" one and that lack of vocabulary is "the foremost predictor of a text's difficulty". In addition, the vocabulary size of students also varies from time to time and also subscribes to the reading development (Nation, 2011; Nation \& Beglar, 2007).

Nation (2001) defines receptive vocabulary as "perceiving the form of a word while listening or reading and retrieving its meaning" (p. 24) and it indicates to the number of words learners know at a certain point of proficiency (Hazenberg, \& Hulstijn, 1996). Reading ability of students is mostly viewed from the vocabulary breadth (or size). Although vocabulary is an essential part of successful academic reading (Schmitt, 2000), it has not been widely researched in Asian countries (Barabadi \& Khajavi, 2017; Catalan, 2003; Fan, 2003; Tang, 2007). In Pakistani public educational institutes, vocabulary is also deemed less important and the most of the ESL/EFL syllabus is exam-based. Students are not imparted with the vocabulary learning strategies to enhance their vocabulary size essential for their reading abilities and language proficiency. In the similar vein, Jamil et al. (2014) also report, "Students at elementary and secondary school level are lagging behind in language competencies especially in English. These deficiencies are usually rooted in weak vocabulary growth" (p. 35). Since vocabulary teaching and learning is less emphasized in the EFL/ESL syllabus especially at tertiary level, students develop their vocabulary size interacting with text books, friends, classroom teachers and watching English movies. Thus, students' vocabulary is deemed as "a dynamic process" (Alharthi, 2014; Hunt \& Beglar, 2005; Nation, 2001) that varies from time to time. To this end, there is a dearth of research on whether students' receptive vocabulary changes over a time period? If yes, does it impact their reading ability? To understand this phenomenon, the current study primarily aims to investigate the development of students' receptive vocabulary size and its relationship with their reading ability at two different points.

\section{IMPORTANCE OF THE STUDY}

To understand a text, readers need to know sufficient vocabulary (Nation, 2011). The relationship between vocabulary and reading comprehension is a complex and dynamic one. This relationship can be split in two different directions: "the effect of vocabulary knowledge on reading comprehension, and the effect of reading comprehension on vocabulary knowledge or growth" (Nation \& Hu, 2000, p. 403). The proposed study 
investigates the impact of receptive vocabulary on reading comprehension because vocabulary seems to be a potential predictor for successful reading comprehension (Zhang \& Anual, 2008).

Zhang and Anual (2008) discovered that §students' vocabulary knowledge at the "2000word and the 3000-word levels" were associated with their reading ability. In another study, Pringprom (2011) administered the bilingual version (English-Thai) Vocabulary levels test and a reading test of multiple choice questions to 300 undergraduates at Bangkok University. The findings revealed that there was a strong correlation between students' receptive vocabulary and reading comprehension. In the similar vein, $\mathrm{Hu}$ and Nation (2000) also assert that readers have to be well acquainted with 5,000 word families so as to comprehend the running words in a novel.

The research study on the relationship between vocabulary size and reading ability of university students in Malaysia, Ibrahim et al. (2016) analyzed VLT and the final scores of students' reading score on English Proficiency Test (EPT). The findings indicated that students' reading ability was closely linked with their vocabulary size. Moreover, Ball and Buller (2017) also investigated the relationship between vocabulary size and reading performance of students. To collect the data, bilingual Japanese version of VST (BJVST), and TOEFL ITP and the GTEC were administered to one hundred Japanese university students. The findings revealed that there was a weak correlation of VST with students' reading comprehension. This study suggested that the bilingual version of vocabulary test (BJVST) was not a handy mean to predict the reading performance of Japanese university students.

In Iranian context, Baleghizadeh and Golbin (2010) also studied the influence of vocabulary size on university students' reading competence. To collect the data, this cross-sectional study administered a vocabulary size test (Nation, 1990), and a reading comprehension test (TOEFL) to Eighty-three first year university students. The findings suggested that there was a positive correlation between vocabulary size and reading ability of students. In another study, Laufer (1992) also concluded her study that there was a moderate to high correlation between vocabulary size and reading comprehension with correlation ranging from ".50 to .75 ." This study also determined the fact that vocabulary size of learners could predict their reading ability.

Addressing to the dynamic nature of vocabulary, Gallego and Llach (2009) documented the receptive vocabulary growth of 224 Spanish EFL learners. The aim of this study was to trace the receptive vocabulary knowledge of these students over the period of four years and to examine the effect of target language exposure on their vocabulary size. Learners were also given ample exposure of the target language from 4th to 7the grade of their studies. Two-thousand frequency vocabulary level test was administered to collect the data. The findings revealed that the vocabulary of students significantly increased as they advanced from one stage to another stage.

The above cited studies have tried to determine the complex relationship of learners' vocabulary breadth or size with their reading comprehension in different social contexts. Additionally, majority of the studies cited above, especially on receptive vocabulary and 
its relationship with reading comprehension, were cross-sectional. As vocabulary development is a "dynamic process" (Hunt \& Beglar, 2005; Nation, 2001), this study aims to establish the relationship of the both variables at two different times while eliciting the data from the same audience. Moreover, this study also provides a deep insight into the scanty knowledge of dynamic nature of vocabulary breadth and its relationship with reading ability of Pakistani university students.

\section{RESEARCH OBJECTIVES}

1. To determine the vocabulary size of Pakistani university students at the beginning and the end of English course.

2. To determine the statistically significant difference, if any, in vocabulary size of Pakistani university students at the beginning and the end of English course.

3. To determine nature of relationship, if any, between vocabulary size and reading comprehension of Pakistani university students at the beginning and the end of English course.

4. To assess the predictability of vocabulary size for the reading ability of Pakistani university students.

\section{METHOD}

This study employed 'follow-up' quantitative research design to determine the development of Pakistani university students' receptive vocabulary size and its relationship with their reading competence at two different points. Dörnyei (2007) states that follow up studies are lucrative for collecting information to measure a change at the micro level.

To measure the receptive vocabulary size of the students, Nation and Beglar's (2007) standardized vocabulary size test (VST) was administered. The VST consists of 140 items and can determine the receptive vocabulary breadth/size of students up to 0 14,000 words with 10 items from each 1000 word-family level. Each right answer on the test is to be multiplied with 100 to calculate the actual vocabulary size of the students (Nation \& Beglar, 2007). For example, if a student hits 13 right answers on the VST test, his actual vocabulary size would be 1300 words. To determine the relationship of vocabulary size of students with their reading comprehension, TOEFL reading test was administered. Prior studied have also used TOEFL reading test to investigate the relationship between vocabulary breadth and reading comprehension (see, Baleghizadeh \& Golbin, 2010; Qian, 1999). The test consisted of four passages. Each reading passage was followed by the questions. The test had 29 questions and a point for each right answer.

The data was collected in two different waves: at the beginning and the end of English language course of six months. All the participants voluntarily participated in both VST and reading comprehension test. All of them assured that they would also be available for the second wave of the data collection. In the first wave of data collection, 123 students participated while the second wave of data collection received the response of 102 students. The rest of 21 students could not participate in the final wave of data collection due to unknown reasons. In this regard, Taris (2000, as cited in Dörnyei, 
2007) states, "There can be multiple reasons for this attrition (or 'mortality'); there may be, for example, logistic ones (non-availability, changing address or telephone number, etc.), or panel members may become ill or simply unwilling to continue because of a lack of time or loss of interest. Such attrition is cumulative because once someone has missed a data collection wave, that person is lost for the remainder of the study" (p. 82).

Therefore, the final data analysis only included the test score of 102 students.

\section{Participants}

The participants of this study included 123 postgraduate students who were enrolled in different departments at University of Balochistan, Quetta, Pakistan. Their age ranged from 22 to 26 years. All of these students were attending the short course of English language: "Functional English language" as a compulsory subject. The key objective of this course is to help these students improve their reading and writing skills in English language since they are required to attempt their final examinations in English language besides few humanity subjects which can be attempted in local languages of Pakistan.

\section{Procedure}

As mentioned above, this study employed follow-up research design in which data was collected in two different waves. In the first wave, students were informed about the nature of the study and they were also assured that their results on both VST and reading comprehension test would not be revealed to anyone and would only be accessed by the one who is doing this research. For this study, we included only those students who also consented to participate in the second wave of data collection. After performing these all formalities and seeking consent from the head of concerned departments, the first author himself conducted VST and reading compression test and each test took almost 35 and 40 minutes respectively.

\section{Data analysis}

For the first research objective of the study, descriptive statistics was performed in SPSS (Version, 21) in which mean scores of students on VST were calculated. To achieve the second research objective of the study, Paired-samples t-test was also performed in the SPSS. Pallant (2013, p. 243) states that this test is beneficial "when you have only one group of people and you collect data from them on two different occasions". For the third research objective, a two-tailed Pearson Product-Moment Correlation test was run, whereas Simple Linear Regression was performed to achieve the fourth objective of the study.

\section{FINDINGS}

To achieve the first objective of the study, descriptive statistics was performed to measure the vocabulary size of the university students at two different points. The results are summarized in the following Table 1: 
Table 1

Students' VST Scores at the beginning and the end of English course

\begin{tabular}{lll}
\hline Vocabulary Size & Mean & SD \\
\hline Beginning of English Course & 35.00 & 4.95 \\
\hline End of English Course & 40.80 & 6.35 \\
\hline
\end{tabular}

Table 1 indicates that the mean score of 121 participants on 14,000 words list at the beginning of English course was $(M=35.00, S D=4.95)$ and $(M=40.80, S D=6.35)$ at the end of English course. Since each point of the test equals to the 100 points (Nation \& Beglar, 2007), hence students' average vocabulary size estimate at the beginning and the end of English course was 35,00 words and 4,090 words respectively.

For the second research objective of the study, Paired-samples t-test was performed in the SPSS. The following Table 2 summarizes the results:

Table 2

Results of Paired-samples t-test

\begin{tabular}{|c|c|c|c|c|c|c|c|}
\hline Vocabulary Size & Mean & sd & $\begin{array}{l}95 \% \mathrm{cc} \\
\text { of the } \mathrm{c}\end{array}$ & $\begin{array}{l}\text { ence interval } \\
\text { ence }\end{array}$ & $\mathrm{t}$ & $\mathrm{df}$ & $\mathrm{p}$ \\
\hline & & & Lower & Upper & 7.90 & 101 & .000 \\
\hline $\begin{array}{l}\text { Beginning of English } \\
\text { Course }\end{array}$ & 35.00 & 4.95 & 4.34 & 7.24 & & & \\
\hline End of English Course & 40.80 & 6.35 & & & & & \\
\hline
\end{tabular}

The Table 2 above indicates that there was a significant increase in the vocabulary size of students at the beginning of English course $(\mathrm{M}=35.00, \mathrm{SD}=4.95)$ and at the end of English course $(\mathrm{M}=40.80, \mathrm{SD}=6.35), \mathrm{t}(101)=7.90, \mathrm{p}<.001$. The mean increase in vocabulary size of students at the end of English course was 5.9 with $95 \%$ confidence interval ranging from 4.34 to 7.24. Moreover, the computation of eta squared statistic (0.34) also revealed the large effect size (Cohen's D).

For the third objective of the study, "a two-tailed Pearson Product-Moment Correlation test" was run in the SPSS. The following Tables 3-4 present the results:

Table 3

Correlation between VST and reading at the beginning of English Course

\begin{tabular}{llllll}
\hline Relationship & $\mathrm{M}$ & $\mathrm{SD}$ & $\mathrm{N}$ & $\mathrm{R}$ & $\mathrm{P}$ \\
\hline Vocabulary at beginning of & 35.00 & 4.59 & 102 & .10 & .28 \\
$\begin{array}{l}\text { English course } \\
\text { Reading Comprehension }\end{array}$ & 6.13 & 2.23 & & & \\
\hline
\end{tabular}

p<.05

Table 4

Correlation between VST and reading at the end of English course

\begin{tabular}{llllll}
\hline Relationship & $\mathrm{M}$ & $\mathrm{SD}$ & $\mathrm{N}$ & $\mathrm{R}$ & $\mathrm{P}$ \\
\hline Vocabulary at beginning of English course & 40.80 & 6.35 & 102 & .76 & .000 \\
Reading Comprehension & 11.14 & 3.23 & & & \\
\hline
\end{tabular}

$p<.001$ 
Table 3 above depicts the fact that there was a small positive link between vocabulary size of students and their reading comprehension at the beginning of English course and the relationship was not significant, $\mathrm{r}=.10, \mathrm{n}=102, \mathrm{p}>.05$. Whereas, that there was a significant and the strong positive correlation between VST and reading comprehension at the end of English course, $r=.76, n=102, p<0.001$ as illustrated in the Table 4 .

For the fourth objective of the study, simple linear regression was run in SPSS. The following Tables 5, 6 and 7 present the results. The Table 5 supports the assumption of the model that vocabulary size of the students can predict their reading comprehension. This model is significant at $\mathrm{F}(1,100)=141.505, \mathrm{p}=.001$.

Table 5

ANOVA result for the best fit model

\begin{tabular}{lllllll}
\hline Model & & Sum of Squares & df & Mean Square & F & Sig. \\
\hline 1 & Regression & 616.444 & 1 & 616.444 & 141.505 & .000 \\
& Residual & 435.634 & 100 & 4.356 & & \\
& Total & 1052.078 & 101 & & & \\
\hline
\end{tabular}

a. Dependent Variable: Reading comprehension

b. Predictor (Constant): Vocabulary size

The Table 6 below presents the model summary depicting a strong positive correlation between students' overall vocabulary size and reading comprehension, at $(r=0.765)$. Moreover, adjusted $(\mathrm{R}$ Square $=0.582$ ) explains how much variance in the reading comprehension of students can be explained by their vocabulary size. In this regard, $58.2 \%$ of reading ability of students can be explained by their vocabulary size. This model illustrates that vocabulary size of students plays a pivotal role in shaping their successful reading comprehension. Additionally, in the Table $7(\beta=0.765)$ reveals the strongest and statistically significant contribution of independent variable (vocabulary size) in explaining the dependent variable (reading comprehension) with $\mathrm{p}>.001$.

Table 6

Predictive Model Summary

\begin{tabular}{lllll}
\hline Mode & R & R Square & Adjusted R Square & Std. Error of the Estimate \\
\hline 1 & .765 & .586 & .582 & 2.08719 \\
\hline
\end{tabular}

Table 7

Coefficients of vocabulary size and reading comprehension

\begin{tabular}{llllll}
\hline Model & \multicolumn{2}{l}{ Unstandardized Coefficients } & $\begin{array}{l}\text { Standardized } \\
\text { Coefficients }\end{array}$ & $\mathrm{T}$ & $\mathrm{p}$ \\
\hline \multirow{3}{*}{ (Constant) } & $\mathrm{B}$ & Std. Error & Beta & -3.88 & .000 \\
Vocabulary size & -5.496 & 1.413 & & 11.89 & .000 \\
\hline
\end{tabular}

a. Dependent Variable: Reading comprehension

Summarizing the results in the Tables 6 and 7 above, it can be seen that vocabulary size of university students predicts their reading ability. The results $\left(\beta=.765, \mathrm{t}_{100}=11.89, \mathrm{p}\right.$ $<.001)$ show that increase in the vocabulary size can also result increase in reading comprehension. Moreover, the strong positive relationship between these two variables 
was found $(\mathrm{r}=.765)$ and the model predicted $58.2 \%$ of the variance. Additionally, the model also emerged quite fit for the data $(\mathrm{F}(1,100)=141.505, \mathrm{p}=.001)$.

\section{DISCUSSION AND CONCLUSSION}

The findings of the first research objective of the study revealed that the average size of students' vocabulary estimate at the beginning and the end of English course was 35,00 words and 4,090 words respectively. This finding begets a question that "how much university students are likely to perform on the reading comprehension of English texts". The understanding of this question can be developed from Nation's (2006) statement that L2 learners need almost 8,000-9,000 words to comprehend the $98 \%-99 \%$ of the text. As far as some unfamiliar words in a text are concerned, learners infer the meaning of those new words from the context. Similarly, Schmitt (2008) states that ESL/EFL learners need to know "8,000-9,000" word families to understand the texts effectively. As the overall vocabulary size of the university students is not satisfactory, Pakistani English language teachers have to look into this matter seriously to help students improve their vocabulary size to cope with reading difficulties which are likely to emanate from lack of vocabulary size.

The findings of the second research objective indicated that a change in the vocabulary of students at the beginning and the end of English course was significant at $(\mathrm{p}<.001)$. This view supports the findings of the study by Gallego and Llach (2009) in which it was determined that the vocabulary of students significantly increased as they advanced from one stage to another stage. In the current study, the average increase over the period of a semester was 590 words that formed their vocabulary of total 4.090 average words. Such a vocabulary size also lags behind the ideal vocabulary size suggested for university students to understand university level texts with an acute ease (Nation, 2006; Schmitt, 2008).

The findings also suggest that vocabulary size of Pakistani students was not according to their education level i.e., the postgraduate level. Consequently, it is not only alarming for their academic reading but it can also negatively impact their academic writing in which the final examinations are conducted in Pakistani educational institutes. These issues are likely to emanate when vocabulary is less prioritized in the syllabus of the target language. As vocabulary is "the determinant factor for reading success" (Stæhr, 2008 , p. 51), Pakistani university teachers need to incorporate vocabulary-building techniques in their teaching as also suggested in the past studies (Nation, 2001). Similarly, drawing upon the unprecedented importance of vocabulary in language learning, Karshen (1989) suggests teachers to devote the considerable amount of time to facilitate learners to increase their vocabulary because it one of the key indicators for language learning success.

The findings of the third objective of the study showed that there was a small positive and non-significant correlation $(\mathrm{r}=.10, \mathrm{p}<.28)$ of 35,00 words with the reading ability of the students at the start of English course. However, 4,090 words had a significant and the positive strong linear relationship $(\mathrm{r}=.76, p<.001)$ with students' reading ability at the end of English course. This finding supports the finding of the study by Qian (1999) 
in which a strong correlation $(\mathrm{r}=.82)$ was found between vocabulary size of students with their reading comprehension on TOEFL reading test. The findings of the study by Zhang and Annual (2008) also confirmed that vocabulary size of students had a close relationship with their English reading comprehension. In the same vein, Baleghizadeh and Golbin (2010) also concluded their study that knowing enough words positively impacts the reading ability of students. Besides reading skills/techniques, vocabulary size seems to shape the reading ability of students in a positive way. Wu and $\mathrm{Hu}$ (2007) also assert that satisfactory vocabulary knowledge regardless of its depth is prerequisite for an effective reading.

The findings of the fourth research objective of this study indicated that the overall vocabulary size of students could predict $(58.2 \%)$ of reading ability of students. This finding compliments the conclusion of the study by Grabe (2011), "there is a fairly straightforward linear relationship between growth in vocabulary knowledge for a text and comprehension of that text" (p. 39). This finding calls for the attention of ESL/EFL teachers and material developers to facilitate students to improve their vocabulary size.

In the light of the view, "without grammar very little can be conveyed, without vocabulary nothing can be conveyed" (Wilkins, 1972, p. 111), this study has tried to draw the importance of vocabulary size (or breadth) and its pivotal role in understanding the university level reading texts. The findings have some pedagogical implications where English language teachers are called for to devise lucrative and extensive reading activities in classrooms since such activities have positive impact on both vocabulary increase and reading ability of learners (Krashen, 2004). Additionally, the predictive model of the study also suggests that vocabulary size is one of the key factors for poor/good reading ability of students. This information also draws the attention of English language teachers, and syllabus designers to facilitate students by devising strategies to acquaint them with maxim new words. We recommend that teachers can develop interest among students by guiding them to look for difficult words in texts and find their meanings by looking up their meaning into dictionaries. And can also encourage them to use those new words in speaking and writing. Teachers can also help students build up their vocabulary by imparting them with vocabulary learning strategies (Schmitt, 2000).

\section{LIMITATIONS AND RECOMMENDATIONS}

As no research is exhaustive in itself, therefore, some directions are also recommended for future studies based on the limitations of the current study. First, this study solely carried out the follow-up study over a period of one semester, therefore the complex nature of change of pattern in the vocabulary size of students cannot be understood thoroughly. Therefore, future studies may replicate the similar study over a period of one year or more to gain the deep knowledge pertinent to the dynamic nature of vocabulary size and its correlation with students' reading ability. Second, the current study emphasized on the impact of vocabulary size (or breadth) on students' reading performance using quantitative research design, and VST and TOEFL reading test as a source of data collection tools. Future studies are recommended to carry out longitudinal mixed method studies in which interviews can be integrated to listen to the voice of 
learners for "how do they improve their vocabulary over the period of time?" Such studies would likely to explore the different vocabulary learning strategies that learners practice for enhancing their vocabulary breadth. Third and final, as the current study solely focused over the role of "dynamic nature of vocabulary size" for successful reading, the future studies are recommended to add the concept of "dynamicity of vocabulary size and depth" and their relationship with reading at different points. Such studies are likely to give theoretical and methodological contributions in second/foreign language learning.

\section{REFERENCES}

Alharthi, T. (2014). The dynamic and incremental features of vocabulary acquisition. International Journal of English Linguistics, 4(6), 70-77.

Baleghizadeh, S., \& Golbin, M. (2010). The effect of vocabulary size on reading comprehension of Iranian EFL learners. LiBRI. Linguistic and Literary Broad Research and Innovation, 1(2), 33-47.

Ball, D., \& Buller, D. (2017). The Relationship between vocabulary size and reading comprehension among Japanese EFL learners. Journal of Inquiry and Research, 106, 110 .

Barabadi, E., \& Khajavi, Y. (2017). The effect of data-driven approach to teaching vocabulary on Iranian students' learning of English vocabulary. Cogent Education, 4(1), $1-13$.

Bauer, L., \& Nation, P. (1993). Word families. International Journal of Lexicography, 6(4), 253-279.

Catalan, R. (2003). Sex differences in L2 vocabulary learning strategies. International Journal of Applied Linguistics, 13, 54-77.

Cheng, C. K. (2007). College English majors' receptive and productive vocabulary knowledge. In Proceedings of the 16th International Symposium and Book Fair on English Teaching (pp. 347-356). Crane Publishing.

Dörnyei, Z. (2007). Research methods in applied linguistics: Quantitative, qualitative and mixed methodologies. Oxford: Oxford University Press.

Fan, M. Y. (2003). Frequency of use, perceived usefulness, and actual usefulness of second language vocabulary strategies: A study of Hong Kong learners. The Modern Language Journal, 87, 222-241.

Fan, M. (2000). How big is the gap and how to narrow it? An investigation into the active and passive vocabulary knowledge of L2 learners. RELC Journal, 31, 105-119.

Gallego, M. T., \& Llach, M. P. A. (2009). Exploring the increase of receptive vocabulary knowledge in the foreign language: A longitudinal study. International Journal of English Studies, 9(1), 113-133. 
Hazenberg, S., \& Hulstijn, J. (1996). Defining a minimal receptive second-language vocabulary for non-native university students: An empirical investigation. Applied Linguistics, 17, 145-163.

Hu, H. C. \& Nation, I. S. P. (2000). Unknown word density and reading comprehension. Reading in Foreign Language, 13(1), 403-430.

Hunt, A., \& Beglar, D. (2005). A framework for developing EFL reading vocabulary. Reading in a Foreign Language, 17(1), 23-59.

Jamil, S., Majoka, M. I., \& Khan, M. S. (2014). A study of vocabulary building in English language curriculum at primary level in Pakistan. Journal of Elementary Education, 24(1), 31-45.

Ibrahim, E. H. E., Sarudin, I., \& Muhamad, A. J. (2016). The relationship between vocabulary size and reading comprehension of ESL learners. English Language Teaching, 9(2), 116.

Kaivanpanah, S., \& Zandi, H. (2009). The role of depth of vocabulary knowledge in reading comprehension in EFL contexts. Journal of Applied Sciences, 9(4), 698-706.

Koda, K. (2005). Insights into second language reading: A cross-linguistic approach. Cambridge, UK: Cambridge University Press.

Krashen, S. (1989). We acquire vocabulary and spelling by reading: Additional evidence for the input hypothesis. The Modern Language Journal, 73(4), 440-464.

Krashen, S. (2004). The power of reading. Portsmouth: Libraries Unlimited.

Laufer, B. (1997). The lexical plight in second language reading: Words you don't know, words you think you know, and words you can't guess. In J. Coady \& T. Huckin (Eds.), Second language vocabulary acquisition: A rationale for pedagogy (pp. 20-34). Cambridge: Cambridge University Press.

Laufer, B. (1992). How much lexis is necessary for reading comprehension? In P. J. L. Arnaud, ed., Vocabulary and applied linguistics (pp. 126-132). Palgrave Macmillan UK.

Nation, I. S. P. (2001). Learning vocabulary in another language. Cambridge: Cambridge University Press.

Nation, I. S. P. (2001). Research into practice: Vocabulary. Language Teaching, 44(1), 529-539.

Nation, I. (2006). How large a vocabulary is needed for reading and listening? Canadian Modern Language Review, 63(1), 59-82.

Nation, I. S. P., \& Beglar, D. (2007). A vocabulary size test. The Language Teacher, 31(7), 9-13.

Pallant, J. (2013). SPSS survival manual: A step by step guide to data analysis using IBM SPSS. Sydney: Allen \& Unwin. 
Qian, D. (1999). Assessing the roles of depth and breadth of vocabulary knowledge in reading comprehension. Canadian Modern Language Review, 56(2), 282-308.

Qian, D. D. (2002). Investigating the relationship between vocabulary knowledge and academic reading performance: An assessment perspective. Language Learning, 52(3), 513-536.

Schmitt, N. (2000). Vocabulary in language teaching. Cambridge: Cambridge University Press.

Schmitt, N. (2008). Instructed second language vocabulary learning. Language Teaching Research, 12(3), 329-363.

Stæhr, L. S. (2008). Vocabulary size and the skills of listening, reading and writing. Language Learning Journal, 36(2), 139-152.

Stahl, S. (2003). Vocabulary and readability: How knowing word meanings affects comprehension. Topics in Language Disorders, 23(3), 241-247.

Tang, E. (2007). An exploratory study of the English vocabulary size of Hong Kong primary and junior secondary school students. The Journal of Asia TEFL, 4(1), 125-144.

Wu, H. Y., \& Hu, P. (2007). Major factors influencing reading comprehension: A factor analysis approach. Sino-US English Teaching, 4(9), 14-18.

Zhang, J. L., \& Anual, B. S. (2008). The role of vocabulary in reading comprehension: The case of secondary school students learning English in Singapore. RELC Journal, 39(1), 51-76.

Wilkins, D. (1972). Linguistics in language teaching. London, UK: Arnold.

Zimmerman, C.B. (1997). Historical trends in second language vocabulary instruction. In J. Coady \& T. Huckin (Eds.), Second language vocabulary acquisition: A rationale for pedagogy (pp. 5-19). Cambridge, UK: Cambridge University Press. 